\title{
Psychology Feud: When the Correct Answer Isn't the Most Valued
}

\author{
William Wozniak | B. Jean Mandernach | Theresa A. Wadkins
}

Psychology Feud, a classroom-based adaptation of the popular American television game show, provides an innovative, engaging opportunity for students to examine popular beliefs and misconceptions concerning general psychological information in a nonthreatening atmosphere. The game can be integrated into introductory psychology courses to (a) identify and discuss common misconceptions about psychology, (b) provide a review of learned information, and (c) measure learning over the course of the semester. The game could also be used to create an opportunity for informal faculty-student interaction.

The use of games as a teaching technique is not new in postsecondary education (McKeachie, 1999). The underlying theory driving most game-based teaching techniques is that active engagement of students in the review of course content will enhance learning of factual material (Bonwell \& Eison, 1991; Fujitsubo, 1998). Games based on American game shows such as Jeopardy (Brewster, 1996; Gibson, 1991; Keutzer, 1993), Trivial Pursuit (Durso, Reardon, \& Wilson, 1994; Tritt, 1993), Hollywood Squares, or Who Wants to be a Millionaire provide a familiar, entertaining format for promoting students' active processing of course material. In addition, these types of trivia-based games utilize questions with single, discrete, correct responses, so that specific course concepts, theories, terms or facts can be reinforced.

Similarly, other teachers have integrated the construction of games by students as an assignment to promote integration and review course material. Research (Berrenberg \& Prosser, 1991; Nigro, 1994; Sternberg, 1999) on the educational value of constructing games based on course concepts indicates that create-a-game assignments are an effective means of engaging students with course material. In addition, create-a-game assignments evoked an enthusiastic response from students. The dual benefits of increased student enthusiasm and enhanced learning support the use of games as an effective contentbased teaching method.
Although there is undoubtedly educational value in the classroom integration of these types of factual games, it is possible to enlarge the use of games to include questions that address matters of "personal opinion.” Miller, Wozniak, Rust, Slezak, and Miller (1996) indicated that students come into the classroom with many preconceived notions of psychology "facts," some of which are erroneous. They also demonstrated that counter-attitudinal advocacy is an effective means of changing those erroneous notions.

We propose that games wherein the "correct" answer to questions is not so apparent may also have pedagogical usefulness. Specifically, games involving "opinion" polling provide a means of engaging students in the active exploration of popular beliefs and misconceptions relevant to course content. The American television game show Family Feud (C) (Johnston, 2006) provides a model for this type of classroom game.

Family Feud (C) pits two families against each other in a contest to name the responses to survey-type questions posed to 100 people (NBC, 2008). Points are awarded for naming the most popular responses to questions such as "Name a gift a man would buy for a woman." The number of points is based on how many of the 100 people gave a particular response. Points are awarded only for responses given by two or more people in the initial survey. Thus rather than testing 
for knowledge of a correct answer, the game tests for knowledge of how most people would respond.

In order to adapt Family Feud(C) to the introductory psychology classroom as a Psychology Feud game, we developed questions that would address some of the misconceptions concerning psychology, administered the questions to the class toward the beginning of the semester, and played Psychology Feud toward the end of the semester using the class' own responses to determine the "correct" answers.

\section{DESCRIPTION OF THE ACTIVITY}

\section{Initial Activity Guidelines}

In order to collect the survey poll responses, the survey questions were presented as a fill-in-the-blank quiz to pretest knowledge about psychology at the beginning of our Introductory Psychology courses. The quiz provided an excellent activity to generate discussion about the range of topics covered by the field of psychology, about the presentation of psychological information in the popular media, and about students' expectations for the course.

Once survey responses were collected, they were compiled to identify the most common responses to each question. Appendix A provides a list of the survey questions we utilized; it is important to note that because there was not necessarily a "correct" answer to every survey question, the range and diversity of responses for some questions was quite high. As such, Appendix A also highlights questions that we found were most likely to show a restricted response range; when we created the final Psychology Feud game, questions with a limited range of common responses (typically fewer than eight different responses) were most applicable to the standard game format.

Game construction consists of selecting target questions (those that revealed a limited response range) and listing the responses ranked from most to least popular. Table 1 displays the survey response data for two questions from one of our Introductory Psychology classes. In this case, we administered the initial survey at the beginning of the semester and re-administered the survey toward the end. For the question "Who is the most influential psychologist today?", it is noteworthy that popular psychologists dropped out of the response list as did nonpsychologists, such as Galileo. For the question "What is the most common mental illness?", the frequency of the response "depression" increased, and other inappropriate responses, such as "craziness," were not given.
Playing Psychology Feud

Psychology Feud is played by two competing teams. To begin, two individuals, one from each team, face off to see which team gains control of that particular question. Once the question is presented, the first person to "buzz in" gets to respond first. Whoever guesses the more popular answer in the survey has the option to play the question or pass it to the other team. After the initial face-off, the team in control, one member at a time, tries to determine all of the answers given to the question. If a team guesses an answer that is not on the board (or fails to respond), they get a "strike"; three "strikes" cause the team to relinquish control of the board. The other team then gets the chance to steal the points if they guess one of the remaining answers. Any remaining answers are then revealed. NBC's Family Feud website (2008) presents a more complete description of the rules.

In the class activity, an instructor selects two groups of five students to form teams; the remaining class members serve as the audience. As the teams compete to guess the most common answers to survey questions, the instructor provides between-question feedback on differences between popular beliefs about psychology and actual psychological information. This type of class activity is an effective review and reflection exercise to provide an integrated summary of course information. The activity also reduces performance pressure because the game focuses not so much on factual (possibly trivial) information but on knowledge of popular responses.

\section{EVALUATION AND CONCLUSIONS}

Psychology Feud, based on the popular Family Feud (C) American game show, provided a unique opportunity in Introductory Psychology courses to meet a range of educational objectives in an engaging, innovative manner. Psychology Feud can be integrated effectively into the course to engage students in a discussion about preconceived notions, prior knowledge, and general misconceptions concerning general psychological information. The enhanced student engagement in addressing common misconceptions about psychology was evident in the lively class discussions (even on the first day of class) and out-of-class interactions concerning course material. Students' enthusiasm for the activity was revealed in a number of open-ended course evaluation comments in which students reported enjoying the unique, interactive nature of Psychology Feud and specifically named this activity as one of the most memo- 
rable aspects of the Introductory Psychology class.

From an instructional viewpoint, an analysis of students' changing (or unchanging) perceptions and beliefs about psychology provides an interesting reflection of student learning throughout the course. For example, when one of the authors asked "Who is the most influential psychologist today?" at the beginning of the course, it was not surprising that "Sigmund Freud" was the most common response. But, it was interesting to note that, at the end of the course, students' perception about the modern influence of Freud had not lessened (in fact, after completion of the course, the percentage of students who listed Freud as the most influential psychologist today increased from $49 \%$ to $72 \%$ ). Although one might be a bit cautious about the value of this shift (considering that the perceptions of many psychologists would likely not reflect students' views on this question), it provides an important reflection point about how an instructors' coverage of course material might lead to this perspective. In a more promising intellectual shift, although Dr. Phil and Dr. Laura (American talk show hosts) were initially identified by students as the second and third most influential psychologists today, neither individual was listed by any student at the conclusion of the class.

Carefully-designed survey questions can be useful when assessing student outcomes for a course. If the survey questions are linked to the instructor's goals for the course, the comparison of the survey responses from the beginning and end of the course can provide information on whether the goals were achieved.

It may be valuable for students to consider how their own survey responses may differ from others' responses and even from their own responses at the beginning of the semester. The observation and discussion of these differences may remind them of (a) the erroneous nature of some popular beliefs, (b) the value of critically assessing popular beliefs about psychology, (c) the value of Introductory Psychology in elevating their personal knowledge base, and (d) the importance of Psychology as a discipline in sorting erroneous popular knowledge from empirically-based knowledge. More direct tests of these claims are left for future researchers.

An interesting side effect of Psychology Feud was evident in the integration of the game as a featured activity in Psychology Week (sponsored by our Psychology Club and Psi Chi Chapter). Psychology Week was designed to enhance students' interest in psychology, encourage students' active participation in department activities, and increase opportunities for informal fac- ulty-student interaction. One of the mainstays of Psychology Week is the students-versus-faculty psychology trivia game. Although the traditional game is generally well-received, ongoing student complaints centered on the unfair nature of the competition due to the faculty's much larger amount of discipline-specific knowledge. Psychology Feud effectively eliminated this concern by providing a lively, competitive environment in which an insightful understanding of common beliefs was more valuable than factual knowledge. Both students and faculty indicated that they not only enjoyed the game, but thought that it was an effective, entertaining means of stimulating informal discussions about psychology.

In summary, the use of Psychology Feud provides an engaging opportunity to engage students, examine student learning, and promote informal student-faculty interaction. While the current game was created to specifically target the discipline of Psychology, the principles underlying this game show approach apply to a wide range of other courses and disciplines. Similarly, while the current investigation examined the application of the game in a face-to-face classroom, the activity has potential to be adapted to the unique considerations of an online class. The value of the game is in the use of popular, preconceived notions about a topic to explore relevant course coverage. The unique nature of the game removes apprehension-based barriers to class discussion that are supported by students' lack of factual knowledge. Through this type of stimulating, active interaction, students can reflect on initial misconceptions, identify ongoing points of confusion, and solidify newly-learned information. 


\section{Author Biographies}

William Wozniak received his B.A. from the University of Notre Dame in 1973 and his M.A. and Ph.D. from Miami University in 1978 and 1983, respectively. He has been employed at the University of Nebraska at Kearney since 1978. He has published in the areas of memory, critical thinking, and the teaching of psychology. His current research interests include irrational belief systems, critical thinking, and embodied cognition. He has also been active in contract research for the Nebraska State Patrol concerning vehicle conspicuity. He has taught numerous courses over the years, including Memory and Cognition, Sensation and Perception, Experimental Psychology, General Psychology, Science and Skepticism, General Psychology, Environmental Psychology, and Death and Dying. He is actively involved in University shared governance and curriculum development.

B. Jean Mandernach, Ph.D. is Research Professor and Director of the Center for Innovation in Research and Teaching at Grand Canyon University. Her research focuses on enhancing student learning through assessment and innovative online instructional strategies. In addition, she has interests in examining the perception of online degrees, the quality of online course offerings and the development of effective faculty evaluation models. Jean received her B.S. in comprehensive psychology from the University of Nebraska at Kearney, an M.S. in experimental psychology from Western Illinois University and Ph.D. in social psychology from the University of Nebraska at Lincoln.

Theresa Wadkins began as an instructor in the Department of Psychology at KSC/UNK in 1990. She received her Master's Degree in clinical psychology at Fort Hays State University after earning her Bachelor's Degree at Kearney State College. After a few years as an instructor, while teaching full-time, she completed her doctorate degree at UNL in Educational Psychology and more recently, she earned a Master's Degree in Forensic Science. She teaches General Psychology, Abnormal Behavior and Society, Death and Dying, Memory and Cognition and Psychology and Criminal Behavior. Dr. Wadkins teaches in a variety of formats including online, tra- ditional lecture and using the personalized system of instruction. She has also developed an abnormal behavior class around popular movies. Her research interests include procrastination, assessment, and a variety of teaching issues. In addition to her duties as an as professor and chair of the department, she volunteers for crisis intervention for emergency responders with the Nebraska Critical Incident Stress Management Team. 


\section{References}

Berrenberg, J. L., \& Prosser, A. (1991). The create-a-game exam: A method to facilitate student interest and learning. Teaching of Psychology, 18(3), 167-169. doi:10.1207/s15328023top1803_9

Bonwell, C. C., \& Eison, J. A. (1991). Active learning: Creating excitement in the classroom. 1991 ASHE-ERIC higher education reports. Washington, DC: Office of Educational Research and Improvement. Retrieved from ERIC database. (ED336049)

Brewster, J. (1996). Teaching abnormal psychology in a multimedia classroom. Teaching of Psychology, 23(4), 249-252. doi:10.1207/ s15328023top2304_15

Durso, F. T., Reardon, R., \& Wilson, D. A. (1994). Neural coding and synaptic transmission: Participation exercises for introductory psychology. Teaching of Psychology, 21(2), 96-99. doi:10.1207/ s15328023top2102_8

Fujitsubo, L. C. (1998). Developing and enhancing successful intelligence in introductory psychology students: An interview with Robert J. Sternberg. Teaching of Psychology, 25(3), 227-231. doi:10.1207/s15328023top2503_19

Gibson, B. (1991). Research methods Jeopardy: Tool for involving students and organizing the study session. Teaching of Psychology, 18(3), 176-177. doi:10.1207/s15328023top1803_13

Johnston, G. (Producer). (2006). Family feud [Television series]. London: Fremantle Media.

Keutzer, C. S. (1993). Jeopardy in abnormal psychology. Teaching of Psychology, 20, 45-46. doi:10.1207/s15328023top2001_11

McKeachie, W. J., \& Gibbs, G. (1999). McKeachie's teaching tips: Strategies, research, and theory for college and university teachers (10th ed.). Boston: Houghton Mifflin Company.

Miller, R. L., Wozniak, W. J., Rust, M. R., Slezak, J., \& Miller, B. R. (1996) Counterattitudinal advocacy as a means of enhancing instructional effectiveness: How to teach students what they do not want to know. Teaching of Psychology, 23(4), 215-219. doi:10.1207/s15328023top2304_2

NBC Universal Media (2008). Family Feud. Retrieved from http:// www.nbc.com/Celebrity_Family_Feud/about/
Nigro, G. N. (1994). Create-a-children's game: An exercise for developmental psychology classes. Teaching of Psychology, 21(4), 243-245. doi:10.1207/s15328023top2104_11

Sternberg, R. (1999). Teaching psychology students to be savvy consumers and producers of research questions. Teaching of Psychology, 26(3), 211-214.

Tritt, D. G. (1993). Teaching an undergraduate lecture/research course in health psychology. Teaching of Psychology, 20(1), 21-28. doi:10.1207/s15328023top2001_4 


\section{TABLE 1}

\begin{tabular}{|c|c|c|c|c|c|}
\hline \multirow{2}{*}{ Question } & \multirow{2}{*}{ Responses } & \multicolumn{2}{|c|}{ Beginning of Course } & \multicolumn{2}{|c|}{ End of Course } \\
\hline & & Frequency & Percentage & Frequency & Percentage \\
\hline \multirow{8}{*}{$\begin{array}{l}\text { Who is the most } \\
\text { influential psycholo- } \\
\text { gist today? }\end{array}$} & Freud & 22 & $49 \%$ & 31 & $72 \%$ \\
\hline & Dr. Phil & 7 & $16 \%$ & - & - \\
\hline & Dr. Laura & 5 & $11 \%$ & - & - \\
\hline & $\begin{array}{l}\text { Current psychology } \\
\text { professor }\end{array}$ & 7 & $7 \%$ & - & - \\
\hline & Gestalt & 2 & $4 \%$ & - & - \\
\hline & Piaget & - & - & 4 & $9 \%$ \\
\hline & Maslow & - & - & 2 & $5 \%$ \\
\hline & $\begin{array}{l}\text { Low frequency } \\
\text { responses }(N=1)\end{array}$ & \multicolumn{2}{|c|}{$\begin{array}{l}\text { Galileo, high school psychology teacher, } \\
\text { Mendel, Pluto, Locke, Kepler }\end{array}$} & \multicolumn{2}{|c|}{$\begin{array}{l}\text { Wundt, Skinner, Watson, Erikson, current } \\
\text { psychology professor }\end{array}$} \\
\hline \multirow{8}{*}{$\begin{array}{l}\text { What is the most } \\
\text { common mental } \\
\text { illness? }\end{array}$} & Depression & 26 & $44 \%$ & 32 & $63 \%$ \\
\hline & ADHD & 12 & $20 \%$ & - & - \\
\hline & Schizophrenia & 4 & $7 \%$ & 8 & $16 \%$ \\
\hline & Mental retardation & 4 & $7 \%$ & 1 & $2 \%$ \\
\hline & Bipolar disorder & 3 & $5 \%$ & 1 & $2 \%$ \\
\hline & Alzheimer's disease & 2 & $3 \%$ & - & - \\
\hline & Anxiety & - & - & 9 & $18 \%$ \\
\hline & $\begin{array}{l}\text { Low frequency } \\
\text { responses }(N=1)\end{array}$ & \multicolumn{4}{|c|}{$\begin{array}{l}\text { hysteria, craziness, low self-esteem, } \\
\text { memory loss, insanity, dyslexia, OCD, } \\
\text { multiple personality disorder }\end{array}$} \\
\hline
\end{tabular}




\section{APPENDIX 1}

Psychology Feud Survey Questions

1. Who is the greatest psychologist of all time?*

2. Who is the most influential psychologist today?*

3. From what discipline did psychology

originally emerge?

4. How many decades has psychology been an independent discipline?

5. What is the most common mental illness?*

6. For what is Sigmund Freud famous?

7. Name one career in psychology NOT related to therapy.

8. Name something you would find in psychologist's office.

9. Name something a psychologist would do in laboratory.

10. Name a reason to see a psychotherapist.

11. Name one of the senses."

12. Name an animal used in psychological research."

13. Other than intelligence, name a psychological trait that will help you get through college.

14. What is something that parents should never do to their kids?

15. How many things can a college student think about at one time?
16. Name a sexual disorder.*

17. Name something for which you would take Valium.

18. Name the age in months when children say their first word.

19. Name the best age to get married.

20. Name something that you lose when you age.

21. What IQ score would a genius get?

22. Name an intelligent animal.

23. Name a famous person who had a psychological disorder.

24. Name a reason for forgetting something.

*Asterisked questions tend to produce a limited number of responses; these questions are more effective for the Psychology Feud game. 